\title{
O ENSINO DE SUSTENTABILIDADE E ÉTICA NOS NEGÓCIOS COM A TAXONOMIA DE BLOOM
}

\author{
TEACHING SUSTAINABILITY AND BUSINESS ETHICS \\ WITH BLOOM'S TAXONOMY
}

Recebido em: 29/09/2012 Aprovado em: 12/11/2012
Avaliado pelo sistema double blind review
Editora Científica: Manolita Correia Lima

\author{
ROBERTO PATRUS robertopatrus@pucminas.br \\ HELENA BELINTANI SHIGAKI \\ DANUSA DIAS REIS COUTINHO \\ CHRISTIANE VILLELA \\ GEORGIANA LUNA BATINGA \\ PONTIFÍCIA UNIVERSIDADE CATÓLICA DE MINAS GERAIS
}

\section{RESUMO}

O presente estudo compartilha a experiência de planejamento, execução e avaliação de uma disciplina de sustentabilidade e ética nos negócios realizada com base na Taxonomia de Bloom. Foram sujeitos da pesquisa alunos de um curso de pós-graduação in company, divididos em duas turmas de i8 e i9 alunos. A análise de dados foi quantitativa em um primeiro momento e qualitativa no segundo, envolvendo a análise de todas as questões que compuseram a avaliação dos alunos. Este estudo oferece uma alternativa de avaliação da aprendizagem coerente com o planejamento dos objetivos propostos para o curso. Concluiu-se que a Taxonomia de Bloom é uma ferramenta que se mostrou adequada para verificação da aprendizagem pretendida na área de sustentabilidade e ética nos negócios e viável para permitir uma devolutiva aos alunos em cada etapa do processo educativo, além de ser prática e útil, contribuindo para o planejamento, organização e controle dos objetivos educacionais.

Palavras-chave: aprendizagem; ética nos negócios; avaliação; sustentabilidade; Taxonomia de Bloom.

\section{ABSTRACT}

This study shares the experience of planning, implementation and evaluation of a sustainability and business ethics course based on Bloom's Taxonomy. Research subjects were students of a post graduate in company course, and divided into two classes of 18 and 19. The data analysis was quantitative, at first, and then qualitative, involving the analysis of all the issues that comprised the student assessment. This study offers an alternative learning assessment consistent with the planning of the proposed objectives for the course. It was concluded that Bloom's Taxonomy is an adequate tool for verifying the required learning in the area of sustainability and business ethics, as well as allowing students to receive feedback from every stage of the educational process. In addition to being practical and useful, it contributes to the planning, organization and control of the educational objectives.

Keywords: learning; business ethics; evaluation; sustainability; Bloom's Taxonomy. 


\section{INTRODUÇÃO}

É cada vez mais frequente, em especial no ensino superior, a criação de instrumentos de verificação que buscam certificar que os objetivos iniciais de uma matéria foram abordados e, de fato, aprendidos pelos alunos. A rigor, uma prova deve verificar quanto os alunos alcançaram nos objetivos educacionais (FERRAZ; BELHOT, 20IO; BLOOM; HASTINGS; MANDAUS, 1983; вLоOм et al., 1972). Para que uma prova ou uma atividade avaliativa cumpra seu propósito, é necessário que os objetivos de aprendizagem estejam previamente formulados e que haja correspondência entre o que se cobra na avaliação e o objetivo pretendido. Com a intenção de ajudar no planejamento, organização e controle dos níveis de aprendizado, uma equipe multidisciplinar e multiacadêmica, liderada por Benjamin S. Bloom, mas com contribuições igualmente relevantes de seus colaboradores - M.D. Englehart, E.J. Furst, w. H. Hille D. Krathwohe-elaboraram uma classificação dos objetivos educacionais na década de 1950. A Taxonomia de Bloom, como ficou reconhecida, é uma tentativa de ordenar hierarquicamente o processo de aprendizagem, com etapas distintas e bem definidas. Taxonomia é um sistema de classificação, que permite estruturar organismos pela hierarquia e pelas relações de evolução, podendo assim ser aplicada a objetivos educacionais. O trabalho desenvolvido identificou que o processo completo de aprendizagem incluía três dimensões: o desenvolvimento cognitivo, o afetivo e o psicomotor.

Uma ampla revisão bibliográfica acerca do tema constatou que o estudo sobre a Taxonomia de Bloom não éfrequentemente encontrado em periódicos brasileiros. Na Revista Brasileira de Educação, Revista de Administração de Empresas (RAE), Revista de Administração Contemporânea, Organização \& Sociedade (o\&s) e Educare não há artigos que tenham utilizado essa abordagem e sequer a citação de Bloom. Estudos em diversas áreas de conhecimento, que utilizam esta metodologia, por sua vez, são encontrados na base de dados do Scielo (7 artigos) e na base de dados da Capes (50 artigos a partir do ano 2000). Dos periódicos classificados no Qualis de Administração, foi encontrado o artigo teórico de Ferraz e Belhot (20I0), 
na revista Gestão e Produção, que atualiza a revisão teórica da taxonomia para a proposição de objetivos educacionais, para um módulo de ensino na área de Engenharia. Em 20ı2, os anais do Encontro Nacional da Associação Nacional de Pós-graduação em Administração (EnANPAD) registraram dois artigos que se valeram da temática: o de Salume et al. (2012), que verifica as habilidade de domínio cognitivo definidas pelo MEC para atender o perfil requerido do administrador por meio do exame ENADE; e o de Monteiro et al. (20I2), que aborda a efetiva existência da hierarquização de seus níveis cognitivos da Taxonomia.

Na literatura internacional, a Taxonomia de Bloom é, ainda hoje, utilizada por muitos estudiosos em seu formato original (CHRISTOPHER; THOMAs; TALLENT-RUNNELS, 2004) e, em alguns casos, com pequenas modificações e novas proposições (CALLISTER, 20IO; KRATHWOHL, 2002; ANDERSON; KRATHWOHL, 200I). É utilizada também, como método para análise de avaliações (BISSELL; LEMONS, 2006; ATHANASSIOU; MCNETT; HARVEY, 2003; LIPSCOMB, I985; BARKER; HAPKIEWICZ, I979;), desenvolvimento de currículo e projetos (BETTS, 2008; NOBLE, 2004; CHRISTOPHER; THOMAS; TALLENT-RUNELS, 2004; CHYUNG; STEPICH, 2003; FOOTE; I998) e atividades relacionadas às supervisões e tomadas de decisão (CAETANO; PERES, 2007; GRANELLO, 2000).

Embora nascida no âmbito da pedagogia, a Taxonomia de Bloom é utilizada, com frequência, em outras áreas do conhecimento. Nas áreas biológicas, é utilizada para medir a aprendizagem do aluno (BETTS, 2008; CROWE; DIRKS; WENDEROTH, 2008), na área de enfermagem, é usada para o desenvolvimento de oficinas de aprendizagem (LARKIN; BURTON, 2008). Seu uso também é aplicado na medicina (ZHeng et al.,2008), na computação algébrica na construção de figuras Lissajous (ANDRADE; CAMPOS, 2005), no e-learning (CHANG; CHAO; SHIH; YANG, 2009), na área de ciências (LORD; BAVISKAR, 2007), na música (HANNA, 2007) e na contabilidade (JUNIOR; PEREIRA; LOPES, 2008). Na área de Administração, seu uso é muito restrito. No ensino de sustentabilidade e ética nos negócios, não foi encontrado nenhum trabalho, o que faz supor que o presente texto seja inédito.

$\mathrm{O}$ estudo da sustentabilidade dentro do ambiente corporativo abre uma possibilidade para que a mesma possa ser evidenciada e praticada 
no contexto organizacional. Percebe-se a cada dia que, mesmo com toda a discussão que há sobre o assunto, pouco ainda se faz nas organizações perante a urgência que se desprende dele, e o administrador, por sua formação, deve ser protagonista nos direcionamentos das organizações a favor dos interesses deste tema. Portanto, a importância da inclusão deste tema por parte de alguns professores abre um espaço inovador e atual para discutir um tema de ampla relevância. Sua abordagem reflete um amadurecimento na academia e no ambiente corporativo, revelando uma congruência em responder ao apelo que está posto. Ainda assim, é possível se deparar com resistências para se incluir o tema dentro de propostas pedagógicas, pois um dos grandes desafios globais da humanidade requer normalmente soluções técnicas e educacionais, que se configurem em mudanças efetivas de hábitos, valores e atitudes.

Neste contexto, deseja-se investigar: qual a importância e consequência do uso da Taxonomia de Bloom no planejamento, execução e avaliação de uma disciplina de Sustentabilidade e Ética nos Negócios? O objeto de análise é um curso in company, formado por 39alunos de uma multinacional. Para isso, foram estabelecidos cinco objetivos para este artigo, a saber: (a) analisar o planejamento da disciplina, que se baseou na citada Taxonomia por meio da análise do plano de ensino representado por um documento formal elaborado pelo professor e entregue no primeiro dia de aula aos alunos; (b) analisar os resultados da avaliação de aprendizagem realizada pelos alunos, (c) investigar em que níveis cognitivos os alunos trabalharam com maior desenvoltura, (d) verificar se as notas dos alunos se distribuíram de acordo com a curva de Gauss e, (e) analisar as questões das provas que envolveram os níveis cognitivos de avaliação e criatividade.

Este estudo se tornou relevante por oferecer uma alternativa de avaliação da aprendizagem coerente com o planejamento dos objetivos propostos para o curso, a fim de facilitar, avaliar e estimular o desempenho dos alunos em diferentes níveis de conhecimento.

Valendo-se da taxonomia de Bloom, pode-se avaliar a aprendizagem dos alunos desde a recordação e compreensão dos conceitos e dados a respeito da sustentabilidade e ética nos negócios até a criação de novos 
processos, ferramentas e alternativas acerca do tema, passando, inclusive, pela aplicação prática dos conceitos teóricos na realidade organizacional. Além de medir o nível de aprendizagem, o uso da Taxonomia permite medir o nível cognitivo alcançado pelo aluno em sua aprendizagem.

$\mathrm{O}$ artigo está estruturado em cinco partes, sendo a primeira essa introdução. A segunda parte traz a fundamentação teórica sobre Taxonomia de Bloom e sobre a sustentabilidade e ética nos negócios. No terceiro momento, é descrito o percurso metodológico que orientou este estudo. Na quarta parte, seguem as análises dos dados e discussão. Por fim, são apontadas algumas considerações e possíveis contribuições que esse estudo permitiu alcançar. 


\section{REFERENCIAL TEÓRICO}

\section{A TAXONOMIA DE BLOOM}

Os objetivos educacionais propostos por Bloom et al. (1972) dividem-se em três domínios: (a) cognitivo: conhecimento, compreensão, aplicação, análise, síntese e avaliação. (b) efetivo: recepção, resposta, valorização, organização e internalização de valores e, (c) Psicomotor: percepção, resposta conduzida, automatismos, respostas complexas, adaptação e organização.

O domínio cognitivo inclui aqueles objetivos vinculados à memória ou recognição (KRAU, 20II), e ao desenvolvimento de capacidades e habilidades intelectuais (PATEL; GROEN; SCOTT, 1988). O domínio afetivo inclui objetivos que descrevem mudanças de interesse, atitudes e valores e desenvolvimento de apreciações e ajustamento adequado.Esses objetivos não apresentam uma formulação precisa (LOMENA, 2006; GUSKEY, 200I). Já o domínio psicomotor, na hierarquia de Bloom, trata de habilidades relacionadas à manipulação de ferramentas ou objetos (BLOOM, 1972).

Para tanto, Bloom classificou a Taxonomia de Objetivos Educacionais como pertencente ao domínio cognitivo, que pode ser definido como o processo de formação do conhecimento, de tal modo que, é possível associar o desenvolvimento do processo cognitivo aos vários estágios pelos quais uma pessoa desenvolve a capacidade de relacionar abstrações (ANDRADE; CAMPOS, 2005). A Figura I ilustra a hierarquia de objetivos educacionais inicialmente proposta por Bloom et al.(1972). 
Figura 1 Objetivos Educacionais

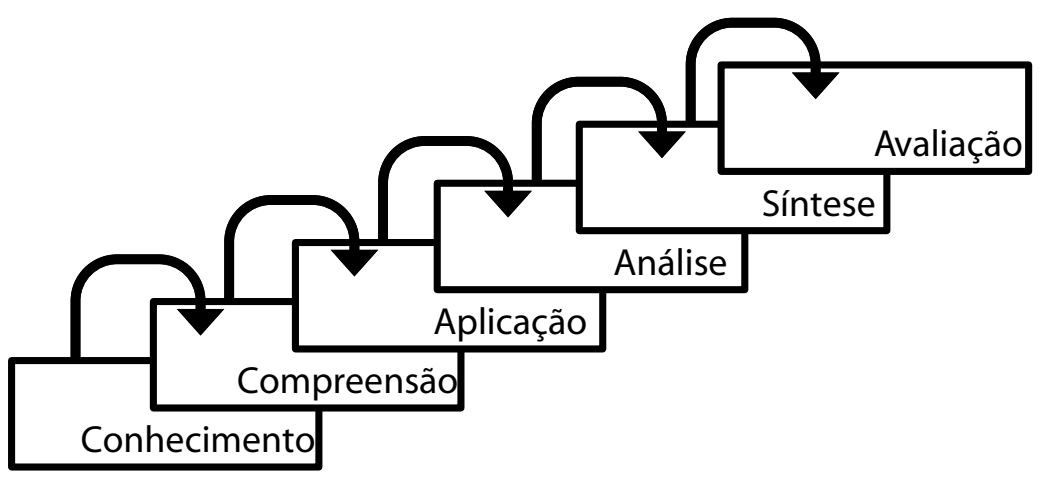

Fonte: Bloom et al. (1972).

Uma das consequências decorrentes dos níveis dessa Taxonomia é a possibilidade de oferecer um guia para a elaboração de objetivos educacionais que se pretendem alcançar. Como os objetivos devem ser mensuráveis, a fim de permitir um diagnóstico da aprendizagem, o seu planejamento deve subsidiar a execução das aulas e a avaliação da aprendizagem dos alunos. A escolha e a definição de tais objetivos devem ser coerentes com os procedimentos, as estratégias e os conteúdos utilizados no processo educacional.

Para alcançar o objetivo, deve-se obedecer a uma hierarquia crescente, que parte do conceito mais simples para o mais complexo e do real para o abstrato. Com base no estímulo do desenvolvimento cognitivo linear é possível atingir altos graus de abstração de um conteúdo. Os processos caracterizados pela Taxonomia de Bloom devem representar resultados de aprendizagem, ou seja, cada nível de conhecimento representa a aquisição de conteúdo produzido pelo aluno, variando de acordo com suas capacidades e seu contexto familiar e cultural. Tais processos são cumulativos, ou seja, um nível cognitivo depende da aquisição do anterior que, por sua vez, dá suporte ao seguinte (GRANELLO, 2000; BLOOM; HASTINGS; MANDAUS, I983; BLOOM et al., 1972). 


\section{A REVISÃO DA TAXONOMIA}

Em 200I, a Associação Norte-americana de Psicologia promoveu um encontro de profissionais de várias áreas e universidades, supervisionados por David Krathwohl, um pesquisador remanescente do grupo original do desenvolvimento da Taxonomia na década de 1950. Liderado por Anderson e Krathwohl (200I), o encontro gerou a publicação da revisão do trabalho de Bloom, na qual foram combinados os tipos de conhecimento a serem adquiridos (dimensão do conhecimento) e o processo utilizado para a aquisição desse conhecimento (dimensão do processo cognitivo).

Devido ao pensamento mais recente de ensino e aprendizagem, foi necessário que novos paradigmas de aprendizagem fossem incorporados para abordar as limitações da primeira Taxonomia proposta por Bloom et al. (1972) e permanecer em dia com as mudanças no pensamento educacional (KRAU, 20II).

A Figura 2 compara os níveis da Taxonomia de Bloom original e revisada, nesta ordem.

Figura 2 Comparação da Taxonomia de Bloom original e revisada

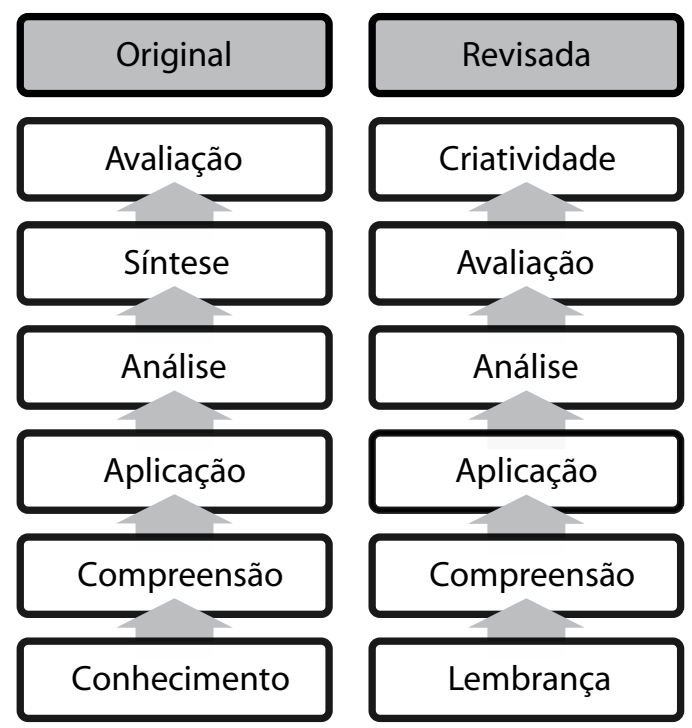

Fonte: Elaborado pelos autores com base em Forehand (2010). 
À primeira vista, as diferenças entre a taxonomia original e a taxonomia revisada não é evidente (KRAU, 20II). Ambas possuem seis categorias. A modificação de nomenclatura ocorreu em três delas e houve também a inversão de posições de síntese (agora criatividade) e avaliação. Os objetivos educacionais cognitivos serão tratados de forma conceitual e individual, conforme abaixo, levando em consideração a Taxonomia original e revisada.

O primeiro nível, lembrança, anteriormente chamado de conhecimento, assemelha-se muito ao comportamento apresentado em uma situação inicial de aprendizagem. O indivíduo adquire e armazena informações que, mais tarde, necessitará evocar, como uma data, um procedimento, um conceito ou um fato específico. Mediante determinada situação, o aluno deve ser capaz de escrever ou identificar o que foi solicitado (FERRAz; BELHOT, 2OIO; SWART, 20IO; STARR; MANARIS; STALVEY, 2008; LORD; BAVISKAR, 2007; KRATHWOHL, 2002).

O segundo nível, compreensão, requer a elaboração ou modificação de um dado ou informação original. Para alcançar essa compreensão o aluno pode modificar mentalmente a comunicação, expressando-a em formula análoga que lhe é mais significativa. Esse objetivo possui três tipos de comportamento, a saber: (a) translação (capacidade de organizar uma comunicação em outra linguagem), (b) interpretação (tratamento da comunicação como uma configuração de ideias) e, (c) extrapolação (estimativa baseada na compreensão) (FERRAZ; BELHOT, 20IO; SWART, 20IO; STARR; MANARIS; STALVEY, 2008; LORD; BAVISKAR, 2007; KRATHWOHL, 2002).

O terceiro nível, aplicação, requer a demonstração do uso de um conhecimento em um problema novo. O aluno deverá aplicar as abstrações apropriadas sem que lhe seja sugerido quais são (FERRAZ; BELHOT, 2OIO; SWART, 20IO; STARR; MANARIS; STALVEY, 2008; LORD; BAVISKAR, 2007; KRATHWOHL, 2002).

O quarto nível, análise, é um processo que propõe identificar aspectos centrais de uma proposição, verificar a validade dos mesmos e relacionar os seus elementos. Este objetivo focaliza o desdobramento do material em suas partes constitutivas, a percepção das suas inter-relações e os modos de 
Organização (FERRAZ; BELHOT, 2OIO; SWART, 2OIO; STARR; MANARIS; STALVEY, 2008; LORD; BAVISKAR, 2007; KRATHWOHL, 2002).

O quinto nível, avaliação, envolve certa combinação de todos os outros objetivos. O processo de avaliar consiste na confrontação de uma informação com critérios que abrangem valores. Tais critérios podem ser internos ao produto avaliado ou externos a ele (FERRAZ; BELHOT, 2OIO; SWART, 2OIO; STARR; MANARIS; STALVEY, 2008; LORD; BAVISKAR, 2007; KRATHWOHL, 2002).

Por fim, o sexto nível, criatividade, anteriormente chamado de síntese, proporciona ao aluno maiores oportunidades de desenvolvimento de comportamento criador. Representa processos nos quais o aluno reúne elementos de informação para compor algo novo, que terá, necessariamente, traços individuais distintivos, singulares (STARR; MANARIS; STALVEY, 2008; HANNA, 2007; KRATHWOHL, 2002).

Com base nessa classificação, espera-se promover o aprendizado do conhecimento de ética nos negócios e na sustentabilidade, desde a apreensão e compreensão de conceitos até a possibilidade de criação de um processo novo, que permita a síntese do repertório intelectual do aluno (seu conhecimento e suas experiências) com o aprendizado desenvolvido.

\section{SUSTENTABILIDADE EMPRESARIAL, ÉTICA NOS NEGÓCIOS E A FORMAÇÃO DE NOVOS LÍDERES}

A sustentabilidade empresarial e a ética assumem neste século um papel central nas dimensões dos negócios, fazendo parte da pauta das estratégias corporativas (IONESCU-SOMERS, 20I2; MATTAR, 2008; GONÇALVES-DIAS et al., 2007).

O modelo de Ética nos Negócios (EN) ensinado no curso baseia-se na proposta de Patrus-Pena e Castro (20Io), que distingue três dimensões de ética: (a) ética da convicção, baseada na definição de valores mínimos norteadores da conduta empresarial, (b) ética da responsabilidade, voltada para as consequências das ações e (c) ética da virtude, "atenta ao desenvolvimento dos sujeitos na conquista de determinados bens mediante práticas compartilhadas” (patrus-pena; castro, 20I0, p. I80). 
A ética da convicção implica a adoção de valores de humanidade que, de algum modo, limitam a busca dos resultados estrategicamente planejados. Nem todos os caminhos são válidos para cumprir as metas estabelecidas. Uma organização ética preocupa-se com os resultados sim, mas sabe o que não deve fazer para realizá-los. Nesse sentido, a ética da convicção é um limite para a ambição da empresa ou da organização da sociedade civil. Esse limite só se realiza se a empresa debater os meios para o alcance dos seus fins. A ética da convicção encontra no código de ética empresarial o instrumento privilegiado para a publicação dos valores, que orientam as decisões organizacionais.

A ética da responsabilidade está relacionada com a gestão do futuro e os efeitos da ação empresarial sobre o meio ambiente, a comunidade e os demais públicos afetados pela conduta da organização. No mundo dos negócios, um dos resultados que se espera das ações de uma organização é o lucro, ou, no caso das organizações de terceiro setor, o retorno financeiro para a manutenção e ampliação das suas atividades. Hoje em dia, essa finalidade econômica é compartilhada pela finalidade social (promoção de melhorias sociais para empregados e comunidade, principalmente) e pela finalidade ambiental (preservação do meio-ambiente e respeito às futuras gerações). A dimensão da responsabilidade reúne o tripé econômico-socialambiental da sustentabilidade, não só da organização, mas do mundo em que vivemos. O relatório de Brundtland afirma que: o desenvolvimento sustentável é um processo de transformação no qual a exploração dos recursos, a direção dos investimentos, a orientação do desenvolvimento tecnológico e a mudança institucional se harmonizam e reforçam o potencial presente e futuro, a fim de atender às necessidades e aspirações humanas. Derivada do conceito de desenvolvimento sustentável, fruto de reflexões e intensos debates ocorridos desde a década de 1960, as várias definições existentes sobre sustentabilidade implicam na manutenção de recursos sem prejudicar suas fontes ou limitar a capacidade de suprimento destes no futuro, para que tanto as necessidades atuais quanto as do futuro possam ser satisfeitas igualmente (AFONSO, 2006). A noção de sustentabilidade implica, 
portanto, uma inter-relação necessária para justiça social, qualidade de vida, equilíbrio ambiental e a ruptura com o atual padrão de desenvolvimento (JACOBI; OLIVEIRA; CASCINO, I998).

Emsentidoestrito,o conceitode sustentabilidade estáepistemologicamente situado sob essa ética, uma vez que a preocupação com as gerações futuras pressupõe o cálculo das consequências da atuação empresarial. Ao contrário da ética da convicção, que privilegia a conformidade de uma ação ao valor previamente assumido, a ética da responsabilidade privilegia o efeito desejado e considera que ele pode, inclusive, justificar a violação de um valor a priori (PATRUS-PENA; CASTRO, 2OIO).

A ética da virtude é a disposição firme e constante para a prática do bem. Virtude é aqui entendida como a transformação dos valores afirmados pela organização em comportamentos cotidianos. Como as decisões de uma organização são decisões de pessoas, a ética da virtude coloca o indivíduo no modelo de ética. Lideranças éticas promovem o hábito de fazer a coisa certa em cada processo decisório, o que exige coragem e virtude (PATRusPENA; CASTRO, 2OIO).

Ora, a ética de uma organização não se reduz à ética da responsabilidade, pois os resultados nem sempre justificam a violação de princípios éticos. Não se reduz, também, a uma ética da conviç̧ão, pois a defesa de valores legítimos pode ter consequências que invalidam a sua intenção. Não se pode desprezar o impacto das decisões em cada um dos públicos da empresa, o que seria irresponsabilidade. Desconsiderar os resultados das ações no processo de tomada de decisão não é apenas ingenuidade, é má gestão. Finalmente, a ética da virtude também não se basta para a formulação de uma ética organizacional. Crer que pessoas virtuosas formam uma organização virtuosa é um exemplo de falácia da composição, classicamente ilustrada pela seguinte proposição: se todas as peças de uma máquina são leves, logo a máquina é leve. A empresa é mais do que as pessoas que a integram. Ela é a soma de processos, tecnologias, culturas e pessoas (PATRUSPENA; CASTRO, 2OIO).

Responsabilidade, dever e virtude articulam-se de forma dinâmica, pois a empresa ao mesmo tempo em que atua com o propósito de promover 
os resultados empresariais, obriga-se a respeitar os direitos humanos nas relações com todos os stakeholders internos e externos (PATRUS-PENA; CASTRO, 20IO, P. I82).

Apesar de alguns avanços, ainda é limitada a visão sobre a importância da transversalidade e o modo como a sustentabilidade e a ética podem agregar valor ao negócio (IONESCU-SOMERS, 20I2). É um desafio desenvolver uma cultura na qual os mecanismos de mercado trabalhem a favor da EN, assim como do desenvolvimento sustentável, da valorização da diversidade, da inclusão social, da economia justa.

Acredita-se que

não há empresa saudável numa sociedade doente, da mesma forma que não existe empresa sustentável sem que haja um mercado igualmente responsável. As empresas são o que o mercado faz delas, e precisamos de um pacto em favor de uma economia ética, a fim de mudar o rosto do mundo (MATTAR, 2008, p.7).

Para a empresa ética, as ações devem estar pautadas na construção de valores com foco num futuro sustentável e respeito ao meio ambiente. Entretanto, a formação das lideranças que promovam tal movimento sustentável e ético precisa ser repensada, reformulada. Alguns caminhos sugerem que é preciso traçar linhas de conduta das atividades de produção e de conhecimento para que estejam em sintonia com esse horizonte civilizatório e sustentável. (BURSZTYN, 200I, p.I2)

E como fica a formação dos líderes de negócios e dos gestores? Afinal, não são eles que irão dar uma nova configuração às empresas amanhã? Há cerca de dez anos, o IMD - Institute for Management Development, na Suíça - vem fazendo uma reflexão sobre esses temas com a ambição de colocar a sustentabilidade no centro da teoria e da prática dos negócios e refletindo sobre as mudanças necessárias na pesquisa e na aprendizagem (IONESCUSOMERS, 20I2). Marcada por paradigmas refletidos pela era industrial como produtivismo, hegemonia da ciência sobre a natureza, especialização e disciplinaridade, a academia atual tem-se confrontado com o desafio de mudar o seu modus operandi (BURSZTyn, 200I). A mudança sistêmica e a integração da sustentabilidade e da ética nos negócios necessitam 
tanto de um trabalho interdisciplinar dentro das escolas como também de desenvolvimento de métodos de ensino-aprendizagem e referências norteadoras para mensuração e avaliação (ANTONello; RUAS, 2005). Assim também a EN carece ainda de muita investigação com consistência empírica para sacramentar os benefícios que ela oferece ao longo do tempo

Alguns pesquisadores têm procurado identificar onde se encontram os maiores desafios para o progresso da educação de executivos. Mas, ainda não há pesquisa e ensino suficientes que sejam: a) relevantes à prática, b) interdisciplinares e c) baseados na solução. (IONESCU-SOMERS, 20I2). As maiores barreiras estão em combinar o conhecimento da implicação da sustentabilidade - e a conscientização de melhores práticas que levem a um bom resultado - com a coragem de desafiar criticamente o preceito do business usual. O mundo vai precisar de pessoas, gestores e líderes que o entendam, que tenham uma perspectiva adiante - e não retrógrada - para enxergar o que está por vir e que pensem crítica e analiticamente (IONESCUSOMERS, 2012).

Trata-se, portanto, de uma nova modalidade de educação e investigação que una a teoria e a prática na busca de compreender o complexo cotidiano do homem complexo. Mais que um processo cognitivo, a aprendizagem organizacional precisa ser uma realização coletiva, inseparável do intercâmbio de experiência, conhecimentos e significados sobre práticas e processos profissionais (GHERARDI, 1999). Contudo, será preciso estimular líderes e gestores à reflexão sobre os sentidos e propósitos de suas ações. Afinal, a transformação só ocorrerá na medida em que entenderem e se enxergarem como protagonistas e corresponsáveis no desenvolvimento de uma criação de valor para toda a sociedade.

Lélé (199i) afirma que não está claro nem para a comunidade acadêmica, e muito menos para os gestores de programas de desenvolvimento, o que representa a sustentabilidade no eixo cultural. Segundo Bursztyn (200I), a aproximação das instituições de ensino superior em relação aos elementos contidos no tema sustentabilidade não é tão recente como a consagração do conceito, que é da segunda metade da década de 1980. O fato é que as abordagens pedagógicas continuam excessivamente centradas 
em modelos ortodoxos, ministrados em formato de palestras e estudos de caso, que passam longe da realidade da maioria dos alunos, dificultando o entendimento sobre a relevância do que estão aprendendo.

Ao longo dos últimos dez anos, uma infinidade de novos programas de sustentabilidade foram realizados, e ouviram-se relatos de vários gerentes sêniores de multinacionais dizerem que "infelizmente, nada disso é muito útil.” (IONESCU-SOMERS, 2OI2).Os modelos das metodologias de ensinoaprendizagem têm papel importante nessa estagnação, pois tendem a articular-se estreitamente com o plano estratégico da empresa. "Entretanto, mesmo associados a uma dimensão estratégica, precisam assumir formas concretas como, por exemplo, iniciativas para resolução de problemas ou para desenvolvimento de novos projetos" (ANTONELLO; RUAS, 2005, p.52)

As metodologias e abordagens empregadas nos programas de pósgraduação lato sensu (especialização) estão "distantes de uma perspectiva de desenvolvimento de competências" e, por sua vez, distantes também da realidade empresarial. Por outro lado, recentemente alguns programas de formação têm procurado inserir simulações em sala de aula ou laboratórios (ANTONELLO; RUAS, 2005, p.52). Mesmo assim, a crítica empresarial volta-se para o distanciamento dessas metodologias das especificidades do ambiente organizacional.

Antonello e Ruas (2005) afirmam também que no caso dos cursos in company, "aproximar os conteúdos teóricos do contexto das atividades profissionais pode resultar em maior consistência na formação de competências gerenciais, o que seria decisivo nos processos de aprendizagem”. Para tanto, é preciso propor recursos didáticos, que possam estimular a visão sistêmica para auxiliar a aprendizagem e, por consequência, o exercício de condutas voltadas para a sustentabilidade e ética nos negócios. O que se deseja, afinal, é uma educação realmente genuína longe de métodos que se limitam ao adestramento ou tecnicismo, e que tem como objetivo central avançar no desenvolvimento de capacidades cognitivas, que levem à crítica, ao questionamento, à cidadania e à procura de autonomia. (BURSZTYN, 200I, p.I7). A habilidade dos profissionais de uma organização em aprender mais rapidamente pode determinar também a vantagem competitiva 
da organização (DE GEUS, 1988), pois a aprendizagem não será apenas reprodução de técnicas, mas reformulação e renovação de conhecimentos com ampliação de competências (ANTONELLO; RUAS, 2005, p.42)

\section{PLANEJAMENTO E AVALIAÇÃO FUNDAMENTADOS NA TAXONOMIA DE BLOOM}

O estudo da Taxonomia de Bloom ultrapassa quase meio século de publicação. No entanto, no momento em que o professor se depara com a tarefa de planejar sua aula, muitos ainda se descuidam dos objetivos inicialmente propostos no planejamento. Quando o assunto é relacionado à verificação da aprendizagem, essa ocorrência é ainda mais comum. Em geral, diante de uma prova, professores e alunos se preocupam em saber qual será a matéria exigida no exame.

A diferença entre o proposto inicialmente no plano de ensino e o que é cobrado do aluno, como resultado do processo de aprendizagem, pode ficar ainda mais explícita no momento da prova final. Não é incomum que, na elaboração dos exames de medição do aprendizado, as abordagens exigidas pelo professor extrapolem o entendimento cognitivo trabalhado em sala de aula. Por esse motivo, os objetivos devem ser mensuráveis (KRAU, 20II) e devem seguir os graus evolutivos como na Taxonomia de Bloom (FERrAz; BELHOT, 20IO).

Kraemer (1996, p. 2) defende que a avaliação deve ser "uma operação descritiva e informativa nos meios que emprega, formativa na intenção que lhe preside e independente face à classificação", explicando que avaliar é o diálogo entre o que foi ensinado e o que foi entendido e praticado.

a Taxonomia de Bloom, mesmo que abstraindo as especificidades sóciohistóricas de cada aluno em particular, ajuda-nos a perceber com mais clareza as ordenações seqüenciais dos objetivos do domínio cognitivo e afetivo e, consequentemente, implicações pré-requisitais de qualquer exigência em termos de conteúdos (ROMÃo, 2005, p. I05).

Uma forma de elaborar o planejamento dos objetivos educacionais é construir uma matriz. Um de seus eixos é o nível cognitivo, desde o conhecimento até a criatividade. O outro eixo da matriz é a unidade programática. Nas 
células resultantes dessas duas variáveis, é elaborado o objetivo educacional. Assim, cada objetivo informaria ao mesmo tempo o conteúdo a ser aprendido (matéria) e o nível cognitivo exigido. Esse procedimento torna a utilização da Taxonomia de Bloom um instrumento que exigirá a informação não apenas do conteúdo da prova, mas também do nível de habilidade cognitiva pretendido em suas questões.

A avaliação de aprendizagem deve ser entendida como um processo contínuo e sistemático, funcional e orientador dos objetivos educacionais propostos ao ensino (PELISSONI, 2009). Sendo a avaliação vista como parte integrante do ensino, é possível superar a visão de que ensinar é a mera transferência de conhecimentos sacramentados, que serão gravados e devolvidos pelo aluno no momento da avaliação.

Um dos fatores mais importantes para o sucesso no ensino é o professor estabelecer com clareza e precisão seus objetivos (MORETTO, 2008). Esse processo serve para orientar o professor quanto à seleção do conteúdo, à escolha de estratégias de ensino e à elaboração de instrumentos para avaliação de desempenho do estudante. Assim, cumpre destacar que esses objetivos não devem ser da esfera exclusiva do professor, devem ser compartilhados com os discentes, a fim de que esses percebam a condução do ensino e saibam o que se esperar deles no curso. Na execução das aulas, o planejamento deve ser apresentado, discutido e, se for o caso, modificado. Cumpre destacar que, ao contrário da visão tradicional, esse processo não é linear, conforme advertem Freitas et al.(2009):

[...] para uma visão linear no processo pedagógico, o planejamento didático é uma sucessão de etapas que começa com a definição dos objetivos, passa pela definição dos conteúdos e dos métodos, pela execução do planejado e finalmente pela avaliação do estudante [...] uma alternativa de ver a organização do trabalho pedagógico em sala de aula abandona essa visão linear e a substitui [...] o que permite organizar o processo de ensino aprendizagem em dois grandes núcleos ou eixos interligados: objetivos/avaliação e conteúdo e método (p. I4).

A avaliação de aprendizagem deixa de figurar no fim do processo e passa a ser justaposta entre os próprios objetivos e, estando o tempo todo presente, 
orienta a atuação na sala de aula. Isso não significa dizer que a avaliação é processual, mas sim que ela ocorre ao longo do processo. A avaliação, na perspectiva que ilumina este artigo, é um simples instrumento que vai permitir ao professor e ao aluno saber que objetivos este alcançou e que objetivos ele precisa ainda alcançar. Zanon e Althaus (2008) preconizam que não é possível conceber a adoção de um único instrumento avaliativo, pois ao aluno só seria dada uma oportunidade de revelar a sua aprendizagem. Permitir aos alunos diversas possibilidades de serem avaliados implica em assegurar a aprendizagem em diversos níveis de uma maneira mais fidedigna.

Freitas et al.(2009) destacam a existência dessa avaliação sob duas perspectivas, tanto no âmbito formal como no informal. Entende-se por avaliação formal aquelas práticas que envolvem o uso de instrumentos explícitos de avaliação, com resultados objetivamente analisados, ao passo que a avaliação informal utiliza-se de juízos de valor subjetivos e invisíveis, mas capazes de influenciar os resultados das avaliações finais, conforme ilustrado pela Figura 3.

Figura 3 Avaliação Fo rmal e Informal

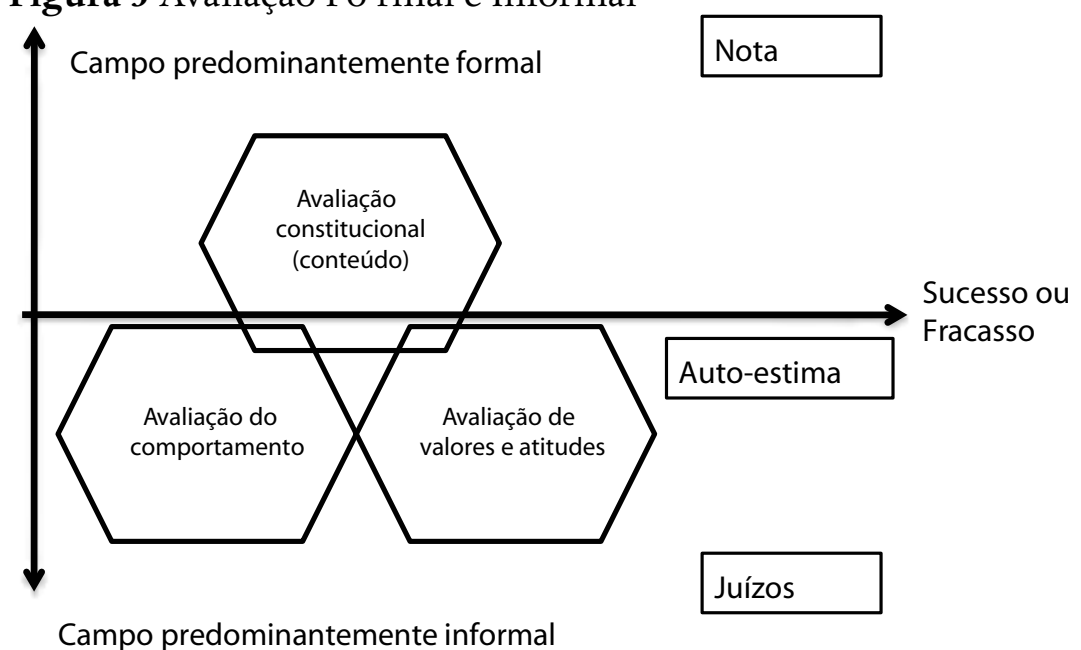

Fonte: Freitas et al. (2009).

Neste trabalho, foi tratada apenas a avaliação constitucional (conteúdo), aquela que permite a aferição de uma nota. 


\section{PROCEDIMENTOS METODOLÓGICOS}

Este estudo se baseia na análise de uma experiência de ensino de uma disciplina de um curso in company de pós-graduação lato sensu em Sustentabilidade e Ética nos Negócios (EN), ministrado a duas turmas, sendo a primeira composta por I8 alunos e a segunda por I9, de uma multinacional instalada proximamente a uma grande capital do Brasil. O curso foi oferecido por uma Instituição de Ensino Superior renomada e reconhecida em território nacional. A estrutura da pesquisa em questão é de ordem descritiva, segundo afirmam Samara e Barros (2009), uma vez que se procurou descrever determinadas situações, comportamentos e habilidades com base nos dados primários, obtidos por meio do plano de curso e da avaliação do curso.

O objetivo geral do artigo foi analisar a importância e consequência do uso da Taxonomia de Bloom no planejamento, execução e avaliação de uma disciplina de Sustentabilidade e Ética nos Negócios. Para isso, foram estabelecidos cinco objetivos para este artigo.

O primeiro objetivo específico se propôs a descrever o planejamento da disciplina em termos de objetivos de aprendizagem. O objeto de análise foi o plano de ensino da disciplina, documento formal elaborado pelo professor e entregue no primeiro dia de aula aos alunos. Os objetivos foram classificados pelo professor no plano de ensino de acordo com os níveis cognitivos da taxonomia de Bloom.

O segundo objetivo específico foi analisar a avaliação (prova e exercícios em grupo) realizada pelo professor com o propósito de verificar a sua coerência com os objetivos propostos no plano de ensino e a sua relação com os níveis cognitivos da taxonomia de Bloom.

O terceiro objetivo foi investigar em que níveis cognitivos os alunos trabalharam com maior desenvoltura.

O quarto objetivo específico foi verificar se as notas dos alunos se distribuíram de acordo com a Curva de Gauss. É de se esperar que a maior parte dos alunos tenha notas intermediárias e que apenas uma pequena parte tenha notas inferiores ou superiores. 
Finalmente, o quinto objetivo específico analisou em particular as questões da prova, que envolveram os níveis cognitivos de criatividade e avaliação, questões essas em que se poderia verificar a capacidade de síntese valendo-se, em particular do conceito de sustentabilidade.

Para os dois primeiros objetivos, a técnica de análise foi a pesquisa documental (GIL, 2009), tendo como objeto o plano de ensino da disciplina. O desenvolvimento da pesquisa documental em muito se assemelha à pesquisa bibliográfica, porém, segundo o mesmo autor, algumas diferenças significativas devem ser assinaladas: (a) extensão de pesquisa mais específica e focada, (b) pode exigir a consulta dos mais diversos tipos de arquivos públicos e/ou privados, (c) o material pesquisado assume os mais diversos formatos, tais como fichas, formulários, vídeos e outros.

Para o terceiro objetivo, a análise do nível de aprendizagem alcançado pelos alunos em cada um dos objetivos educacionais, que a avaliação contemplava, foi feita considerando-se o aproveitamento total na questão. Assim, o aluno atingiu o objetivo proposto quando suas notas nas questões de um determinado nível cognitivo foram o máximo. Essa escolha se justificou em função do propósito de verificar o nível cognitivo em que os alunos trabalharam com maior facilidade e desenvoltura.

Para o quarto objetivo, foi elaborada a Curva de Gauss, conforme os resultados analisados, com o propósito de verificar se o aproveitamento dos alunos obedeceu ou não a uma distribuição normal. A distribuição normal, também conhecida como Distribuição de Gauss, é realizada com base na média e desvio padrão de uma parcela da população, possibilitando verificar a distribuição normal da curva com base nas notas dos alunos.

Já, em relação ao quinto objetivo específico, a análise realizada foi de caráter qualitativo. Seu objeto foi a questão da prova que exigia capacidade cognitiva de avaliação e criatividade. As respostas foram analisadas buscando-se identificar em que nível cognitivo o aluno desenvolveu a sua resposta. 


\section{ANÁLISE DOS DADOS}

A análise dos dados está dividida em seções, conforme os objetivos específicos propostos. Assim, a primeira seção diz respeito à descrição do planejamento da disciplina com base no plano de ensino. A segunda seção apresenta a matriz de avaliação realizada pelo professor, por meio de prova e exercícios em grupo, a fim de checar a coerência com os objetivos propostos no plano de ensino e a relação das questões com os níveis cognitivos da taxonomia de Bloom. A terceira seção contempla a análise do nível de aprendizagem alcançado pelos alunos em cada um dos objetivos educacionais da avaliação. A quarta seção verifica se o aproveitamento dos alunos obedece a uma distribuição normal, por meio da Curva de Gauss. A quinta seção apresenta a análise qualitativa das respostas de avaliação e criatividade.

\section{O PLANEJAMENTO DOS OBJETIVOS EDUCACIONAIS}

O plano de ensino da disciplina foi concebido com base na Taxonomia de Bloom, tanto no que tange à elaboração dos objetivos educacionais quanto no que diz respeito às estratégias de avaliação. O conteúdo programático da disciplina foi dividido em cinco unidades, sendo eles: introdução, ética da convicção, ética da responsabilidade, ética da virtude e ética nos negócios como integração das três éticas. Observou-se aqui que o tema da sustentabilidade não ganhou a relevância merecida, uma vez que as unidades programáticas devem expressar o nome da disciplina. O tema da sustentabilidade aparece sob a égide da ética da responsabilidade e é exigido nas questões mais complexas da prova, aquelas que contemplam os níveis cognitivos de avaliação e criatividade, como será visto na seção seguinte.

O Quadro i ilustra a planilha de objetivos educacionais da disciplina. A elaboração e planejamento da matriz de objetivos se fizeram importantes para nortear a sequência dos conteúdos, que foram aplicados durante a disciplina, bem como para orientar o processo da avaliação. A primeira coluna é constituída pelas unidades do curso, a segunda coluna pelos níveis da taxonomia de Bloom e a terceira pela descrição dos objetivos. 
Observou-se que a classificação dos objetivos educacionais em seus respectivos níveis cognitivos amplia a sua elaboração para além dos objetivos do nível de conhecimento de conceitos, exigindo do professor a reflexão sobre os principais conceitos que o aluno deve não só saber $\mathrm{e}$ compreender, mas também aplicar. A elaboração dos objetivos da disciplina no nível cognitivo da análise exige do professor ser capaz de pensar num mesmo fenômeno apoiado em abordagens aparentemente contraditórias. Essa capacidade se faz necessária para que o professor possa cobrar do seu aluno a defesa de uma mesma decisão com argumentos tanto da ética da conviç̧ão quanto da ética da responsabilidade. Finalmente, a elaboração de objetivos cognitivos de avaliação e criatividade exige do professor abertura de paradigma para que possa avaliar a síntese do aluno com flexibilidade e sem preconceitos.

Quadro 1 Matriz de objetivos educacionais

\begin{tabular}{|c|c|c|}
\hline Unidade & Nível & Descrição \\
\hline \multirow[b]{3}{*}{ Introdução } & & $\begin{array}{l}\text { Descrever as condições para a constituição da ética nos } \\
\text { negócios como disciplina acadêmica. }\end{array}$ \\
\hline & & Definir o que é ética \\
\hline & & $\begin{array}{l}\text { Apontar a finalidade da ética, suas dimensões e seu fun- } \\
\text { damento. }\end{array}$ \\
\hline \multirow[b]{2}{*}{ Ética da Convicção } & & $\begin{array}{l}\text { Descrever o processo decisório baseado na ética da con- } \\
\text { vicção. }\end{array}$ \\
\hline & & $\begin{array}{l}\text { Explicar o papel do código de ética empresarial na formu- } \\
\text { lação de uma ética empresarial. }\end{array}$ \\
\hline \multirow{2}{*}{$\begin{array}{l}\text { Ética da } \\
\text { responsabilidade }\end{array}$} & & $\begin{array}{l}\text { Descrever o processo decisório com base na ética da res- } \\
\text { ponsabilidade. }\end{array}$ \\
\hline & & Definir stakeholder. \\
\hline Ética da virtude & & Definir o que é virtude. \\
\hline Integração & Lembrança & Definir a unidade de estrutura dos contrários. \\
\hline
\end{tabular}




\begin{tabular}{|c|c|c|}
\hline Unidade & Nível & Descrição \\
\hline Ética da Convicção & & $\begin{array}{l}\text { Reconhecer o processo de tomada de decisão baseado na } \\
\text { ética da convicção. }\end{array}$ \\
\hline \multirow[t]{2}{*}{$\begin{array}{l}\text { Ética da } \\
\text { responsabilidade }\end{array}$} & & $\begin{array}{l}\text { Reconhecer o processo de tomada de decisão baseado na } \\
\text { ética da responsabilidade. }\end{array}$ \\
\hline & & $\begin{array}{l}\text { Identificar valores presentes em práticas rotineiras na orga- } \\
\text { nização. }\end{array}$ \\
\hline Ética da virtude & & Relacionar ética da virtude e governança. \\
\hline Integração & Compreensão & $\begin{array}{l}\text { Compreender a unidade de estrutura dos contrários } \\
\text { apoiada na análise dos valores de segurança no trabalho e } \\
\text { de respeito ao meio ambiente. }\end{array}$ \\
\hline Ética da Convicção & & $\begin{array}{l}\text { Elaborar argumentos em favor de uma decisão fundamen- } \\
\text { tos na ética da convicção. }\end{array}$ \\
\hline $\begin{array}{l}\text { Ética da } \\
\text { Responsabilidade }\end{array}$ & & $\begin{array}{l}\text { Elaborar argumentos em favor de uma decisão fundamen- } \\
\text { tados na ética da responsabilidade. }\end{array}$ \\
\hline Ética da virtude & & Estabelecer rotinas no ambiente organizacional que sejam \\
\hline Integração & Aplicação & $\begin{array}{l}\text { Analisar casos do Banco Real e da Natura como exemplos } \\
\text { de integração entre a ética da convicção e a ética da res- } \\
\text { ponsabilidade. }\end{array}$ \\
\hline $\begin{array}{l}\text { Ética da Convicção } \\
\text { Ética da } \\
\text { Responsabilidade }\end{array}$ & & $\begin{array}{l}\text { Distinguir em um debate, os argumentos baseados na ética } \\
\text { da convicção, daqueles baseados na ética da responsabili- } \\
\text { dade. Distinguir em um debate, os argumentos baseados } \\
\text { na ética da responsabilidade, daqueles baseados na ética } \\
\text { da convicção. }\end{array}$ \\
\hline Ética da virtude & Análise & $\begin{array}{l}\text { Verificar em propagandas, serviços e embalagens de pro- } \\
\text { dutos, se os valores afirmados pela empresa em seu código } \\
\text { de ética se fazem presentes de forma habitual, como pro- } \\
\text { cedimento com os stakeholders. Analisar práticas organiza- } \\
\text { cionais nas áreas de vendas, marketing e prestação de ser- } \\
\text { viços, à luz do modelo de ética nos negócios, identificando } \\
\text { cada uma das abordagens éticas presentes. }\end{array}$ \\
\hline Integração & Avaliação & $\begin{array}{l}\text { Propor modificações nas práticas organizacionais da área } \\
\text { de vendas, marketing e prestação de serviços, à luz do } \\
\text { modelo de ética nos negócios. }\end{array}$ \\
\hline Integração & Criatividade & $\begin{array}{l}\text { Criar estratégias inovadoras que representem a integração } \\
\text { do modelo proposto de ética nos negócios. }\end{array}$ \\
\hline
\end{tabular}

Fonte: Elaborado pelos autores com base no plano de ensino disponibilizado pelo professor responsável pela disciplina. 


\section{O PLANEJAMENTO DA AVALIAÇÃO}

O Quadro 2 apresenta as questões de avaliação indicadas no plano de ensino da disciplina.

Quadro 2 Matriz de avaliação da aprendizagem

\begin{tabular}{|c|c|c|}
\hline Módulo & Nível & Descrição \\
\hline \multirow{3}{*}{\multicolumn{2}{|c|}{ Introdução }} & $\begin{array}{l}\text { Quais as condições para a constituição da ética nos negócios } \\
\text { como disciplina acadêmica? }\end{array}$ \\
\hline & & Defina o que é ética. \\
\hline & & $\begin{array}{l}\text { Descreva a finalidade da ética, suas dimensões e seu funda- } \\
\text { mento. }\end{array}$ \\
\hline \multirow[b]{2}{*}{$\begin{array}{l}\text { Ética da } \\
\text { Convicção }\end{array}$} & & $\begin{array}{l}\text { Qual o critério ético que norteia a tomada de uma decisão, } \\
\text { tomando-se por referência a ética da convicção? }\end{array}$ \\
\hline & & $\begin{array}{l}\text { Qual o papel do código de ética empresarial na formulação } \\
\text { de uma ética empresarial, que oriente a tomada de decisão na } \\
\text { empresa? }\end{array}$ \\
\hline \multirow{2}{*}{$\begin{array}{l}\text { Ética da } \\
\text { Responsabilidade }\end{array}$} & \multirow[b]{4}{*}{ Lembrança } & $\begin{array}{l}\text { Qual o critério ético que norteia a tomada de uma decisão, } \\
\text { tomando-se por referência a ética da responsabilidade? }\end{array}$ \\
\hline & & Defina o que é stakeholder. \\
\hline Ética da virtude & & Defina o que é virtude. \\
\hline Integração & & Defina o que significa a unidade de estrutura dos contrários. \\
\hline $\begin{array}{l}\text { Ética da } \\
\text { Convicção }\end{array}$ & & $\begin{array}{l}\text { Reconheça o processo de tomada de decisão baseado na ética } \\
\text { da convicção (exercício em grupo). }\end{array}$ \\
\hline \multirow[t]{2}{*}{$\begin{array}{l}\text { Ética da } \\
\text { Responsabilidade }\end{array}$} & & $\begin{array}{l}\text { Reconheça o processo de tomada de decisão baseado na ética } \\
\text { da responsabilidade (exercício em grupo). }\end{array}$ \\
\hline & & $\begin{array}{l}\text { Todos os empregados da indústria } A B C \text { são orientados para } \\
\text { estacionar os seus carros de modo a facilitar a saída sem necessi- } \\
\text { dade de manobra. Qual o valor presente nessa medida? Por quê? }\end{array}$ \\
\hline Ética da virtude & & Qual a relação entre ética da virtude e governança corporativa? \\
\hline Integração & Compreensão & $\begin{array}{l}\text { Crie um exemplo que demonstre a unidade de estrutura dos } \\
\text { contrários (use provérbios, casos, histórias, imagens, etc, para } \\
\text { demonstrar a unidade entre os contrários). }\end{array}$ \\
\hline
\end{tabular}




\begin{tabular}{|c|c|c|}
\hline Módulo & Nível & Descrição \\
\hline $\begin{array}{l}\text { Ética da } \\
\text { Convicção }\end{array}$ & & $\begin{array}{l}\text { Elabore argumentos em favor de uma decisão fundamentados } \\
\text { na ética da convicção (exercício em grupo). }\end{array}$ \\
\hline $\begin{array}{l}\text { Ética da } \\
\text { Responsabilidade }\end{array}$ & & $\begin{array}{l}\text { Elabore argumentos em favor de uma decisão fundamentados } \\
\text { na ética da responsabilidade (exercício em grupo). }\end{array}$ \\
\hline Ética da virtude & & $\begin{array}{l}\text { Quando os preços do Supermercado Trevo saem da promoção, } \\
\text { é comum encontrá-los nas gôndolas e seus preços mais caros } \\
\text { no caixa. Quando percebida essa diferença, os consumidores se }\end{array}$ \\
\hline Integração & Aplicação & $\begin{array}{l}\text { gevoltam, gerando empresa. Marque a alternativa que melhor transforma } \\
\text { o respeito ao consumidor em uma prática habitual da empresa. } \\
\text { a) sempre que o consumidor reclamar da diferença de preços } \\
\text { na gôndola e no caixa, o gerente deve ser chamado pelo caixa } \\
\text { e devolver o valor para o cliente; b) a empresa deve evitar fazer } \\
\text { promoções; c) a empresa deve fazer a gestão da quantidade } \\
\text { de cartazes e de rótulos com os preços promocionais de modo } \\
\text { a promover a sua total retirada quando terminada a oferta; d) } \\
\text { a empresa deve aperfeiçoar o sistema de computador para } \\
\text { melhorar o controle de preços; e) a empresa deve escrever um } \\
\text { código de ética empresarial e registrá-lo em cartório. }\end{array}$ \\
\hline $\begin{array}{l}\text { Ética da } \\
\text { Responsabilidade }\end{array}$ & & $\begin{array}{l}\text { Do ponto de vista da ética da convicção, uma grande empresa } \\
\text { de petróleo elegeu a segurança e o meio ambiente como limita- } \\
\text { dores na busca de resultados econômicos. Um dos diretores con- } \\
\text { sidera que nada deve parar a produção. Para este diretor, colocar } \\
\text { a ética como um limitador na busca de resultados econômicos é } \\
\text { utópico. Elabore um argumento para convencê-lo da vantagem } \\
\text { de privilegiar a segurança e o meio ambiente, utilizando a lógica } \\
\text { da ética da responsabilidade. }\end{array}$ \\
\hline Ética da virtude & Análise & $\begin{array}{l}\text { Pesquise por propagandas da Iveco na internet, copie o link e } \\
\text { identifique: a) os valores presentes; b) a coerência entre esses } \\
\text { valores e os valores presentes no código de ética; c) o stakehol- } \\
\text { der-alvo; d) o objetivo almejado pela propaganda e seus prová- } \\
\text { veis resultados com diferentes stakeholders (exercício em grupo). }\end{array}$ \\
\hline Integração & Avaliação & $\begin{array}{l}\text { Proponha modificações nas práticas organizacionais à luz do } \\
\text { modelo de EN }\end{array}$ \\
\hline Integração & Criação & $\begin{array}{l}\text { Crie inovações que representem a integração do modelo pro- } \\
\text { posto de ética nos negócios. }\end{array}$ \\
\hline
\end{tabular}

Fonte: Elaborado pelos autores com base na avaliação disponibilizada pelo professor responsável pela disciplina.

A matriz de avaliação elaborada pelo professor foi entregue aos alunos junto com o plano de ensino e foi apresentada como roteiro de avaliação do curso. Ao final, o aluno, excetuando as questões previstas para a realização 
em trabalhos de grupo, deveria entregar as respostas para cada uma das perguntas da matriz, cada uma delas correspondente a um objetivo de aprendizagem, que representava o encontro entre um conteúdo e um nível cognitivo. A avaliação, portanto, não configurou exatamente uma prova, mas um roteiro de questões, divididas de acordo com o nível cognitivo exigido.

A avaliação foi aplicada a duas turmas, uma composta de 18 alunos e outra de 19, no nível de Pós-graduação lato sensu.Os alunos das turmas foram avaliados nos níveis de lembrança, compreensão, aplicação, análise e avaliação e criatividade.

Observou-se coerência entre os objetivos de aprendizagem e o que foi exigido na avaliação. A entrega da matriz de avaliação junto com o plano de ensino causou estranheza, visto tratar-se de uma avaliação. É o caso de se perguntar se a elaboração das respostas em casa facilita a aprendizagem como desejado ou se facilita apenas o bom aproveitamento. De qualquer forma, a elaboração de uma matriz de objetivos e outra matriz de avaliação permite ao professor avaliar não apenas o conteúdo que o aluno apreendeu, mas também em qual nível cognitivo ele trabalha com maior facilidade.

\section{A AVALIAÇÃO DA APRENDIZAGEM}

Considerando que a avaliação não obedeceu aos requisitos tradicionais de uma prova, sendo entregue antecipadamente aos alunos, junto com o planejamento da disciplina, considerou-se, para efeito da avaliação da aprendizagem, que somente as notas máximas em cada questão seriam demonstração de efetiva aprendizagem por parte dos alunos. Vale dizer que a análise feita aqui não foi realizada pelo professor, mas pelos autores desse artigo, com vista a avaliar a importância da taxonomia de Bloom no ensino da disciplina em questão.

Os resultados foram analisados de modo quantitativo por meio da tabulação de todas as notas dos alunos de ambas as turmas, fornecidas pelo professor. A Tabela I mostra a porcentagem de alunos que acertou a totalidade das questões de cada nível cognitivo. 
Tabela 1 Porcentagem de alunos das turmas 1 e 2 com aproveitamento total, por nível cognitivo

\begin{tabular}{|lll|}
\hline Nível Taxonomia de Bloom & Turma 1 (\%) & Turma 2 (\%) \\
\hline Lembrança & $44,4 \%$ & $14,3 \%$ \\
\hline Compreensão & $16,7 \%$ & $66,7 \%$ \\
\hline Aplicação & $100 \%$ & $90,5 \%$ \\
\hline Análise & $66,7 \%$ & $81 \%$ \\
\hline Avaliação e Criatividade & $44,4 \%$ & $21 \%$ \\
\hline
\end{tabular}

O nível de aplicação, das duas turmas, teve melhor índice de aproveitamento quando comparado aos outros níveis da hierarquia. Parece haver uma correlação nos resultados dos níveis de lembrança, aplicação e avaliação e criatividade da Turma I. Essa correlação pode sugerir que alunos que obtiveram melhor lembrança $(44,4 \%)$ dos conceitos ensinados em sala de aula conseguiram desenvolver aplicabilidade (I00\%) para o conteúdo aprendido e, consequentemente, serem capazes de realizar a avaliação do conteúdo e propor novas ideias $(44,4 \%)$. Porém, encontra-se uma discrepância no que tange à compreensão (I6,7\%) e o nível de aplicação (Ioo\%), uma vez que se torna difícil vislumbrar como aplicar conceitos não compreendidos. Neste caso, pode-se conjecturar o desenvolvimento da capacidade de aplicação prática, por meio da utilização de conhecimentos anteriormente adquiridos aos conceitos ensinados no curso. Também é possível que os alunos tenham dificuldade de comunicação da compreensão dos conceitos, visto que conseguem aplicá-lo, mas não conseguem expressá-lo de forma clara e correta. Outra hipótese que merece investigação posterior é a de que os alunos não estudaram o material de leitura, atendo-se mais às recordações do que fora dito em sala de aula. Assim, sugere-se um estudo mais aprofundado posteriormente, pois tal estudo não foi objeto desse artigo.

O Gráfico I indica a porcentagem de alunos que foram capazes de atingir a proposta do curso em cada nível da hierarquia. Ela apresenta em forma de tabela os dados apresentados na Tabela I em ambas as turmas. 
Gráfico 1 Porcentagem de alunos das turmas 1 e 2 com aproveitamento total, por nível cognitivo

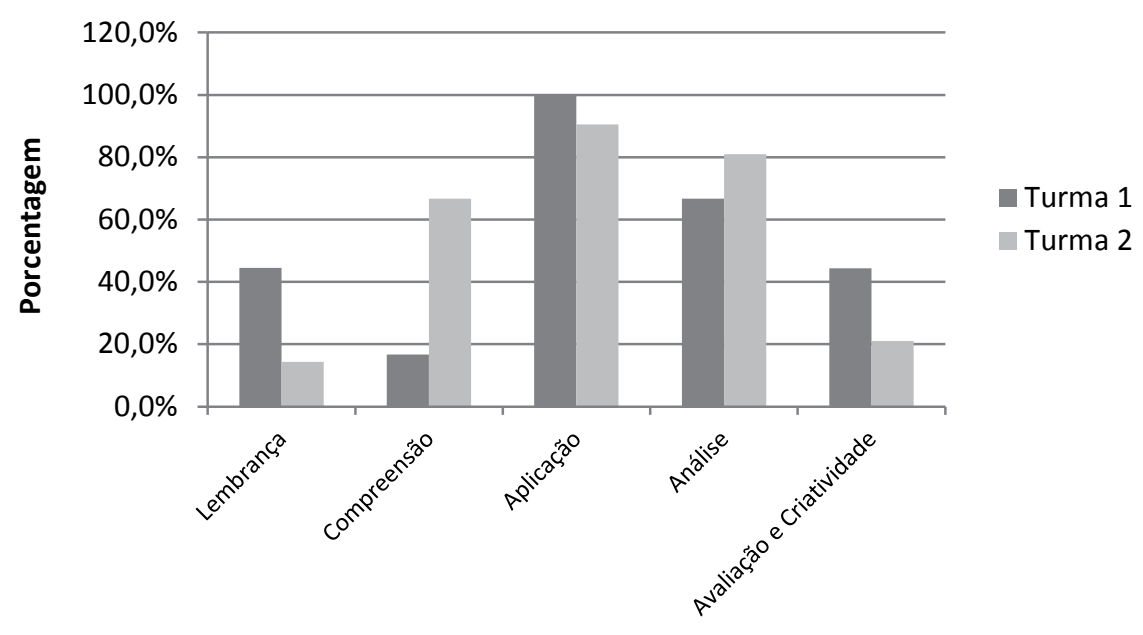

Niveis Taxonomia de Bloom

Da análise do aproveitamento total dos alunos, pode-se concluir que a performance nos níveis de avaliação e criatividade, avaliados em conjunto, foi relativamente pequena na Turma 2 (21\%) e significativo na Turma I $(44,4 \%)$. Curiosamente, o aproveitamento na categoria "aplicação" foi excelente, colocando em dúvida a hierarquização dos níveis cognitivos proposta por Bloom (GRANELLO, 2000; BLOOM; HASTINGS; MANDAUS, I983; BLOOM et al., 1972).

\section{A DISTRIBUIÇÃO DAS NOTAS DOS ALUNOS}

O desempenho geral de todos os alunos pode ser observado pelas Figuras 4 e 5 representadas pela curva de Gauss, geradas pelo software Minitab, onde é possível verificar que a maioria dos alunos se estabelece próxima à média (turma I: $88,83 \%$ e turma 2: 90,36\%). 
Figura 4 Turma 1

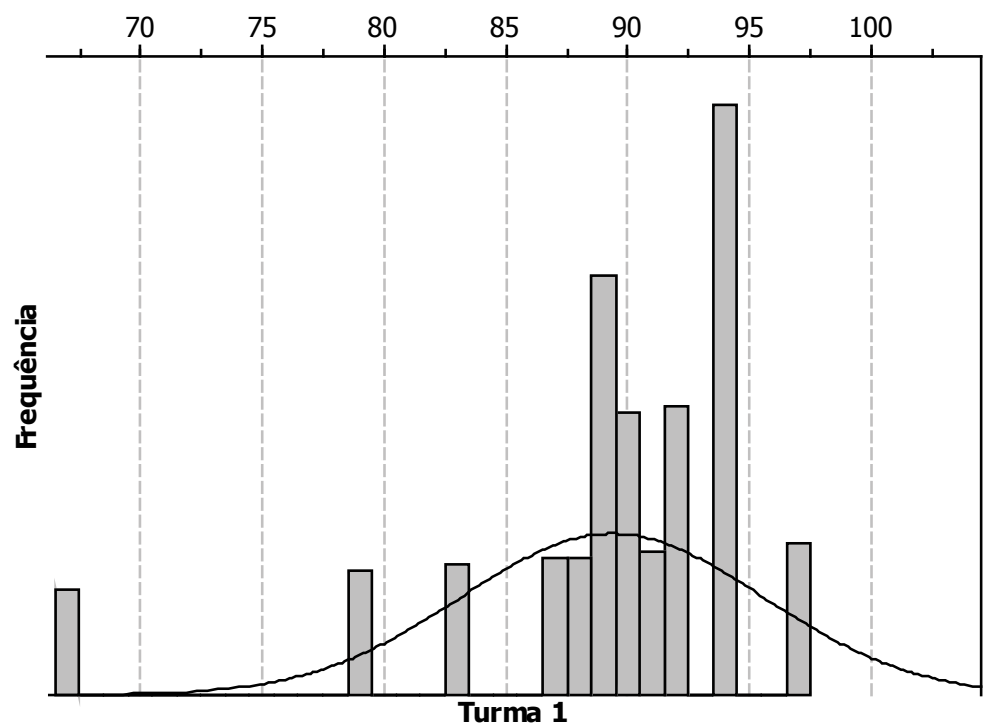

Mean 89,34

Figura 5 Turma 2

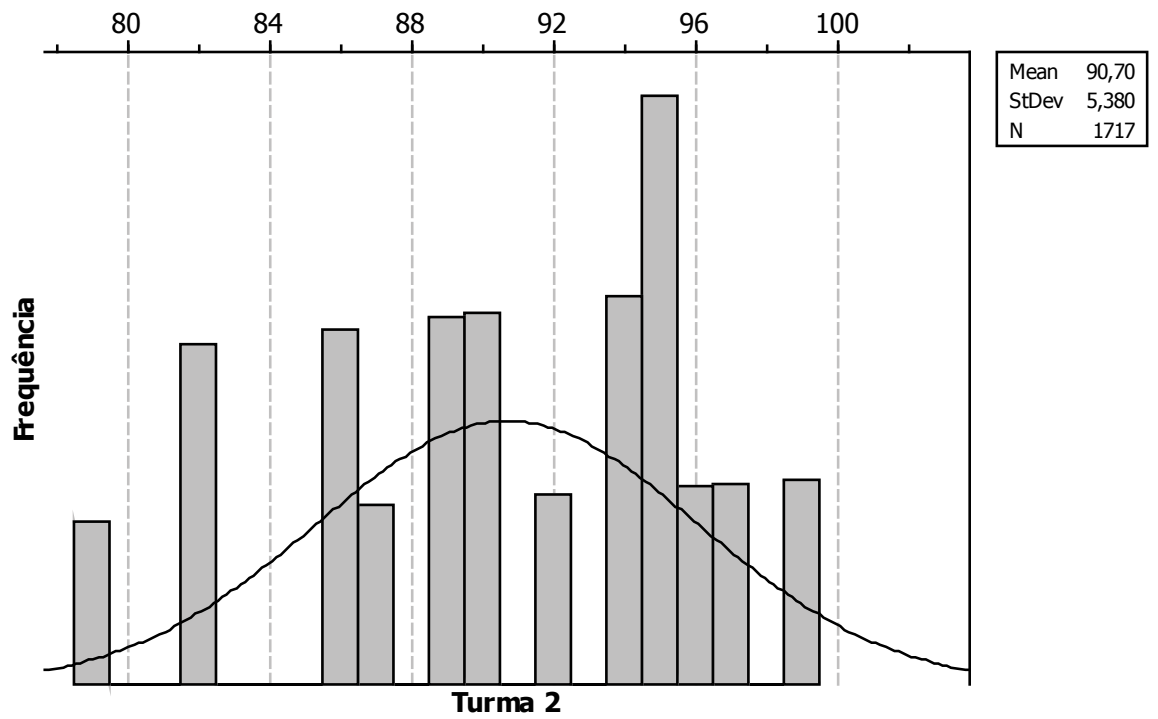


Os resultados das notas finais entre os alunos revelam que, dependendo da forma como os pontos são distribuídos entre as questões da avaliação, o aproveitamento pode ser satisfatório ou não. Se essas questões tivessem valor correspondente à sua importância em termos de aprendizado, a nota final dos alunos seria bem menor. O que se observa é que não basta apenas identificar os objetivos do curso em todos os níveis cognitivos, mas é importante explicitar que objetivos são considerados fundamentais e quais outros são considerados importantes, mas não fundamentais. Como se trata de um curso in company, é de supor-se que o nível de aplicação tenha sido mais valorizado que os demais. Entretanto, considerando que a sustentabilidade é um novo modo de se pensar na gestão, e que as estratégias inovadoras que a contemplam só poderiam ser verificadas nas questões que pressupunham criatividade, seria possível valorar essas questões de modo diferente. Caso essas questões valessem mais, poder-se-ia aventar a hipótese de que alguns alunos teriam dificuldade de obtenção da média.

Enfim, o uso da taxonomia de Bloom, na determinação dos objetivos e a sua correlação com a avaliação exige maior reflexão sobre como valorar as questões de cada nível cognitivo. O que é mais importante em termos de objetivos de aprendizagem é o que deve ser mais valorado em termos de avaliação? Ou devem-se valorar as tarefas mais complexas do ponto de vista cognitivo apenas para distinguir os melhores alunos dos demais?

\section{NÍVEIS COGNITIVOS DE AVALIAÇÃO E CRIATIVIDADE}

Os dados da pesquisa demonstraram que $44,4 \%$ dos alunos da Turma i e 21\% dos alunos da Turma 2 conseguiram desenvolver plenamente as capacidades cognitivas de avaliação e de criatividade, as mais complexas de acordo com a taxonomia utilizada. Com base em uma análise qualitativa das respostas às questões que exigiam essas habilidades, procurou-se identificar o nível cognitivo alcançado nas respostas. Vale recordar que foi solicitado ao aluno que ele propusesse modificações em práticas organizacionais à luz do modelo estudado, e também que ele criasse inovações que representassem a integração do modelo proposto. 
Os Gráficos 2e 3, respectivamente turmas i e 2, ilustram a distribuição dos resultados qualitativos especificamente com relação à questão aplicada para mensurar o nível de avaliação e criatividade, sendo que, os autores classificaram o conteúdo qualitativo da mesma, de acordo com a Taxonomia de Bloom. O nível de hierarquia está identificado no gráfico juntamente com a porcentagem de alunos que alcançaram este nível, sendo NR (não responderam), aplicação, análise, avaliação e criatividade.

Gráfico 2 Alunos Turma 1

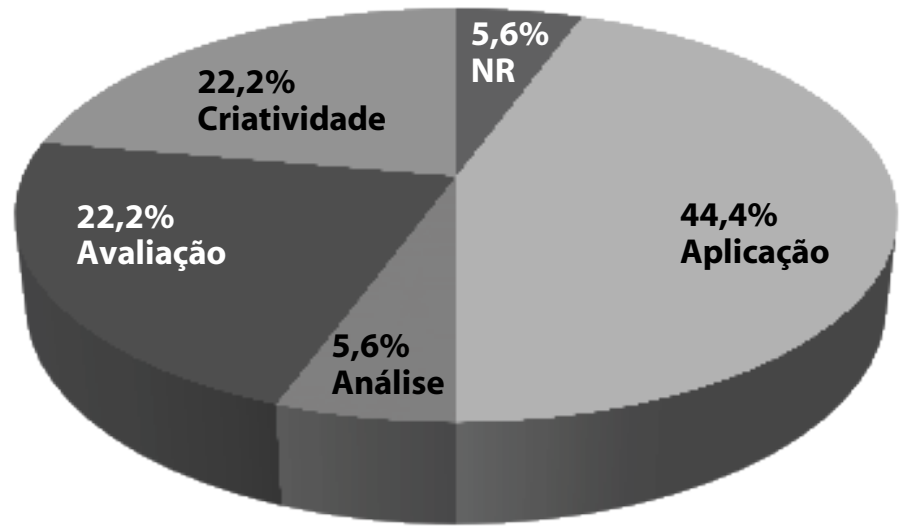

(*) Níveis superiores de aprendizagem, segundo Taxonomia de Bloom

Gráfico 3 Alunos Turma 2

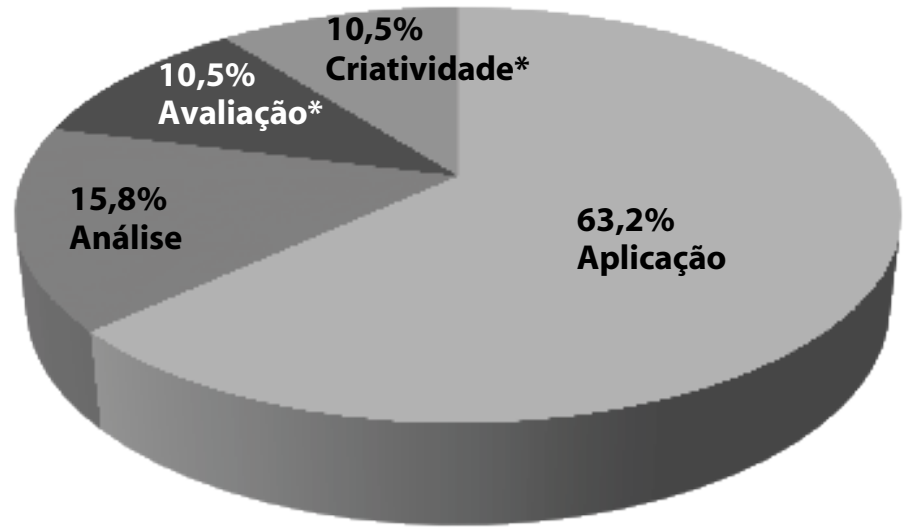

(*) Níveis superiores de aprendizagem, segundo Taxonomia de Bloom 
O nível cognitivo de avaliação envolve a combinação e confrontação de uma informação sobre critérios vinculados aos valores. Já o nível de criatividade proporciona ao aluno maiores oportunidades de desenvolvimento de comportamento singular, único e original. Como as duas questões exigiam propostas de modificações ou inovações, elas foram consideradas em conjunto. Como a sustentabilidade encontra fundamentos tanto na ética da convicção (defesa da vida, das pessoas e do planeta) como na ética dos resultados (consequências para as pessoas, para o meio ambiente e para o mercado), esperava-se que o conceito de sustentabilidade estivesse presente nas proposições.

Dos alunos das turmas i e 2, que atingiram respectivamente $44,4 \% \%$ e $21 \%$ de aproveitamentos da última questão avaliada, nota-se que $44,4 \% \mathrm{e}$ 63,2\% conseguiram redigir respostas coerentes com o nível de aplicação, baseadas na classificação qualitativa desenvolvida pelos autores. Na turma I, oito alunos conseguiram atingir um nível máximo de aplicação em sua resposta de avaliação e criatividade. Já na turma 2, I2 alunos alcançaram este nível, considerado mínimo pelos autores. O nível de análise na turma I $(5,6 \%)$ foi menor que o da turma 2 ( $15,8 \%)$. E, quando comparados com os resultados obtidos pela turma 2, nos níveis de avaliação e criatividade (ambos com 10,5\%, totalizando 2I\%), os resultados sugerem um potencial criativo maior da turma I em relação à turma 2, uma vez que um percentual relativamente significativo da turma I conseguiu redigir respostas coerentes com o nível de avaliação e criatividade (ambos com 22,2\%), que são os níveis mais altos da hierarquia avaliada, totalizando $44,4 \%$.

Como exemplo de respostas dadas no nível de aplicação, tem-se:

- Para evitar desperdícios no banheiro da Instituição pode-se instalar novas torneiras que possuam sensores para abri-las. (aluno I, turma I)

- Ao final de cada disciplina, nós alunos temos que preencher o formulário da avaliação da disciplina e do professor. Porém, as avaliações são impressas individualmente, gerando um alto volume de cópias (...) a sugestão é a de criar uma única avaliação para economizar. (aluno II, turma I)

- Muitos estabelecimentos vendem serviços e produtos como tops de linha, enganando clientes (...) para tentar agir com ética (...) fica a sugestão de 
mostrar o produto que está sendo aplicado, em especial o rótulo. (aluno 7, turma 2)

Acima do nível de aplicação há o nível de análise. Neste nível somente um aluno da turma I e três da turma 2 foram capazes de atingi-lo. Para ilustrar, têm-se alguns exemplos de respostas:

- Atitudes como: incentivar a utilização consciente de energia elétrica no ambiente (...) sob o ponto de vista da EN compreenderia: a ética da convicção, por prezar pela sustentabilidade ecológica; a ética da responsabilidade, visto que o consumo seria reduzido e a ética da virtude, visto que o valor de sustentabilidade seria rotineiramente praticado. (aluno I5, turma I)

- Poderia haver uma caixa de sugestões distribuída pela empresa (...) na qual os funcionários poderiam selecionar os itens mais importantes na ética nos negócios. Com tais dados nas mãos, a diretoria poderia alinhar as sugestões (...) com os anseios da organização. (aluno2, turma 2)

No nível de avaliação, quatro alunos da turma i e dois alunos da turma 2 se apresentaram neste nível, estando mais próximos do nível de criatividade. Para tanto, os exemplos abaixo ilustrarão este nível:

- Ligar para os clientes antecipando futuras reclamações, evitando perdas, saturação e troca de operadoras (...). Com esta medida, a operadora ganha na fidelização de clientes que estarão mais satisfeitos. (aluno 4, turma I)

- Os clientes que estão esperando o caminhão estão deixando de faturar e o prazo extenso gera descontentamento dos solicitantes. Para atender o quesito agilidade seria necessário rever os prazos de entrega, deixando os caminhões semi-montados. (aluno 6, turma 2)

Por fim, quatro alunos da turma I e dois alunos da turma 2 obtiveram aproveitamento de Ioo\% na última questão, oferecendo, portanto, respostas relacionadas às práticas criativas, tais como:

- Para um transporte mais eficiente seria interessante, no painel luminoso, do ônibus aparecer o horário que o mesmo saiu do ponto final e que horas sairá o próximo (...). Com isso, os passageiros podem planejar suas viagens e o valor de respeito com o usuário de transporte público ficaria presente. (aluno 3, turma I) 
- Desenvolver um veículo elétrico para aproveitamento da energia solar para alimentação de sistemas secundários dos veículos (ar condicionado, som, iluminação, etc), representando economia de combustível (...). (aluno 9, turma 2)

Observa-se que nas questões de criatividade, o conceito de sustentabilidade está implícito, tanto do ponto de vista ambiental, como do ponto de vista econômico e social. Esse dado revela que o modelo de ética nos negócios estudado, quando busca contemplar as teorias que o compõem, integra o conceito de sustentabilidade de modo satisfatório. Entretanto, nem todos os alunos são capazes de chegar a tal nível. Fica a questão: como promover a evolução do aluno em termos cognitivos? 


\section{CONSIDERAÇÕES FINAIS}

O mundo vai precisar de pessoas, gestores e líderes que o entendam, que tenham uma perspectiva adiante - e não retrógrada - para enxergar o que está por vir e que pensem crítica e analiticamente (IONESCU-SOMERS, 20I2). Patrus-Pena e Castro (2010) recomendam que a disciplina de ética nos negócios articule os dois campos que a constituem de forma integrada, que permita inserir a sustentabilidade na prática organizacional de forma cotidiana. É necessário criatividade, exigência de repertório e experiência prática na área de sustentabilidade. Neste contexto, desenvolveu-se o estudo sobre a utilização da Taxonomia de Bloom na disciplina de EN e sustentabilidade, na tentativa de comprovar a aquisição de visão sistêmica do conhecimento.

Com base nesse estudo, pode-se concluir que a Taxonomia de Bloom é uma ferramenta prática e útil, que contribui para o planejamento, organização e controle dos objetivos educacionais relacionados ao ensino de ética nos negócios e sustentabilidade. No objeto de estudo analisado, observou-se a vinculação direta entre os objetivos de aprendizagem e a avaliação da aprendizagem, como recomendam Freitas, et al. (2009) e Pelissoni (2009).

Com base na disciplina de Ética nos Negócios, oferecida em um curso de pós-graduação lato sensu, foi feita a análise dos resultados de um exercício previamente programado. A estratégia utilizada para um curso de is horas atendeu à recomendação de Zanon e Althaus (2008), que sugerem o uso de mais de um instrumento avaliativo. Entretanto, a extensa lista de objetivos pareceu dificultar a realização dos mesmos. Poucos foram os alunos que desenvolveram todas as habilidades cognitivas de criatividade e avaliação, as mais complexas de todas. Entretanto, a grande maioria dos alunos foi capaz de aplicar os conceitos na realidade organizacional. Fica a seguinte pergunta: um curso deve estabelecer a priori o nível cognitivo mais desejado para a aprendizagem? Ou deve deixar que os alunos desenvolvam as suas competências nos níveis em que se sentem mais confortáveis? 
Os cinco primeiros níveis da Taxonomia de Bloom possibilitaram a construção de uma sistemática clara e precisa para a disciplina. Essa sistemática, por sua vez, pode ser multiplicada como ferramenta para análise de aprendizagem em diversos campos de ensino. Vale ressaltar que, nessa construção, um dos fatores mais importantes para o sucesso no ensino é o professor estabelecer com clareza e precisão seus objetivos (MORETTO, 2008).

No processo de avaliação da aprendizagem, Kraemer (1996) afirma que avaliar é o diálogo entre o que foi ensinado e o que foi entendido e praticado. A avaliação utilizada na disciplina de EN se valeu de um longo conjunto de questões, respondidas pelos alunos em grupo e individualmente.

O aproveitamento de todos os alunos que participaram do curso foi de $88,83 \%$ na turma I e 90,36\% na turma 2. É importante considerar que, dependendo do método escolhido pelo professor, para a aplicação da avaliação, é possível que ocorram alterações nos resultados finais. Produzir uma devolutiva para os alunos participantes, a cada etapa concluída, pode ser uma contribuição que dará oportunidade à aprendizagem.

Para alcançar o objetivo, recomenda-se começar do conceito mais simples para o mais complexo e do real para o abstrato, havendo assim, correlação e interdependência entre os níveis. Um nível cognitivo depende da aquisição do anterior e, por sua vez, dá suporte ao seguinte (GRANELLO, 2000; BLOOM; HASTINGS; MANDAUS, 1983; BLOOM et al., 1972). Outrossim, esse estudo indica um questionamento com relação à utilização prática da taxonomia de Bloom em cursos de pós-graduação in company. Para que tal questionamento sobre a taxonomia de Bloom possa ser confirmado, deve-se multiplicar o mesmo estudo em públicos distintos. 


\section{REFERÊNCIAS}

AFONSO, C. M. Sustentabilidade: caminho ou utopia? São Paulo: Annablume, 2006. ANDERSON, L. W.; KRATHWOHL, D. R.(Eds.). A Taxonomy for Learning, Teaching and Assessing: A Revision of Bloom's Taxonomy of Educational Objectives. New York: Longman, 2001.

ANDERSON, D. R.; SWEENEY, D. J.; WILLIAMS, T. A. Estatística aplicada à administração e economia. São Paulo: Pioneira-Thomson Learning, 2002.

ANDRADE, D.; CAMPOS, M. Análise do processo cognitivo na construção das figuras de Lissajous. Revista Brasileira de Ensino de Física, v. 27, n. 4, p. 587-591, 2005.

ANTONELLO, C. S.; RUAS R. Formação Gerencial: Pós-graduação Lato Sensu e o Papel das Comunidades de Prática. RAC, v. 9, n. 2, p.35-58, 2005.

ATHANASSIOU, N.; MCNETT, J. M.; HARVEY, C. Critical thinking in the management classroom: Bloom's taxonomy as a learning tool. Journal of Management Education, v. 5, n. 27, p. 533, 2003.

BARKER, D.; HAPKIEWICZ, W. G. The effects of behavioral objectives on relevant and incidental learning at two levels of bloom's taxonomy. Journal of Educational Research, v. 6, n. 72, 1979.

BETTS, S. C. Teaching and assessing basic concepts to advanced applications: using bloom's

taxonomy to inform graduate course design. Academic one File, v. 11, n. 3, p. 99, 2008.

BISSELL A.; LEMONS, P. A new method for assessing critical thinking in the classroom. Bioscience, v. 1, n. 56, p. 66- 72, 2006.

BLOOM, B.; ENGELHART, M. D.; FURST, E. J.; HILL, W. H.; KRATHWOHL, D. R. Taxonomia de Objetivos Educacionais: Porto Alegre: Globo, 1972.

BLOOM, B. S.; HASTINGS, J.; MANDAUS, G. F. Manual de Avaliação formativa e somativa do aprendizado escolar. São Paulo: Pioneira, 1983.

BURSZTYN, M. (Org.). Ciência, ética e sustentabilidade. 2. Ed. São Paulo: Cortez, 2001

CAETANO, K. C.; PERES, H. H. C. Metodologia para estruturação de hipertexto aplicado ao curso de enfermagem. Acta Paul Enferm. v. 20, n. 2, p. 175-179, 2007.

CALLISTER, P.D. Time to Blossom: An Inquiry into Bloom's Taxonomy as a Hierarchy and Means for Teaching Legal Research Skills, v. 102, n. 2, 2010.

CHANG, W.; CHAO, L. R.; SHIH, T. K.; YANG, H. Using S-P chart and bloom taxonomy to develop intelligent formative assessment tool, v. 4, n. 7, 2009.

CHRISTOPHER, M. M.; THOMAS, J. A.; TALLENT-RUNNELS, M. K. Raising the bar:

Encouraging high level thinking in Online Discussion forums. Roeper Review, v. 3, n. 
26, p. 166-171. 2004.

CHYUNG; STEPICH, Applying the "congruence" principle of bloom's taxonomy to designing online instruction. Quarterly Review of Distance Education, v. 3, p. 317-330, 2003.

CROWE, A.; DIRKS, C.; WENDEROTH, M. P. Biology in Bloom: Implementing Bloom's Taxonomy to Enchance Student Learning in Biology. Lifes Sciences Education, v. 7, p. 368-381, 2008.

CUMMINGS, A. L.; MURRAY, H. G. Ego development and its relation to teacher education. Teaching \& Teacher Education, v. 5, n. 1, p.21-32, 1989.

DE GEUS, A. P. Planning as learning. Harvard Business Review, v. 66, n. 2, p.70-75, 1988.

FERRAZ, A. P. C. M.; BELHOT, R. V. Taxonomia de Bloom: revisão teórica e apresentação das adequações do instrumento para definição dos objetivos instrucionais. Gestão e Produção, v. 17, n. 2, p. 421-431, 2010.

FREITAS, L. C.; SORDI, M. R. L.; MALAVASI, M. M. S; FREITAS, H. C. L. Avaliação Educacional: Caminhando pela contramão. Rio de Janeiro: Vozes, 2009.

FOREHAND, M. Bloom's Taxonomy - Emerging Perspectives on Learning, Teaching and Technology. The University of Georgia, 2010.

FOOTE, C. Student-generated higher order questioning as a study strategy. Journal of Educational Research, v. 2, n. 92, p. 107, 1998.

GIL, A.C. Como Elaborar Projetos de Pesquisa. 4.ed. São Paulo: Atlas, 2009.

GHERARDI, S. Learning as problem-driven or learning in the face of mystery? Organization Studies, v. 20, n. 1, p. 101-124, 1999.

GONÇALVES-DIAS S. L. F.; TEODÓSIO A. dos S. de S.; BARBIERI J. C. Desafios e Perspectivas da Sustentabilidade: Caminhos e Descaminhos na Gestão Empresarial. In: ENCONTRO NACIONAL SOBRE GESTÃO EMPRESARIAL E MEIO AMBIENTE, 9., 2007, Curitiba. Anais... Curitiba, 2007.

GRANELLO, D. H. Encouraging the cognitive development of supervisees: Using bloom's taxonomy in supervision. CounselorEducation \& Supervision, v. 1, n. 40, p. 31. 2000.

GUSKEY, T. R. Benjamin S. Bloom contributions to curriculum, instruction, and school learning. Annual Meeting of the American Educational Research Association, 2001.

HANNA, Wendell. The new Bloom's Taxonomy: Implications for Music Education. Arts Eduaction Policy Review, v. 108, n. 4, 2007.

IONESCU-SOMERS, A. Centro de Sustentabilidade Corporativa do Institute for Management Development (IMD-CSM), Suíça. Disponível em: <http://www. ideiasustentavel.com.br/2012/06/os-dois-lados-da-moeda-academica/\#comment-2673>. Acesso em 10/07/2012.

JACOBI, P.; OLIVEIRA, J. F.; CASCINO, F. (Orgs.). Educação, meio ambiente e cidadania: 
reflexões e experiências. São Paulo: SMA, 1998.

JUNIOR, J. J.; PEREIRA, D. M.; LOPES, J. E. Análise das habilidades cognitivas requeridas dos candidatos ao cargo de contador na administração pública federal, utilizando-se indicadores fundamentados na taxonomia de Bloom. R. Cont. Fin., v. 19, n. 46, p. 108-121, 2008.

KRAEMER, M. E. P. A avaliação da aprendizagem como processo construtivo de um novo fazer. Campinas: UNICAMP, 1996.

KRATHWOHL, D. R. A revision of bloom's taxonomy: An over view. Theory Into Practice, v. 4, n. 41, p 212. 2002.

KRAU, S. D. Creating Educational Objectives for Patient Education Using the New Bloom's Taxonomy. Nursing Clinics of North America, v. 463, n. 3, p.299-312, 2011.

LARKIN, B.G.; BURTON, K.J. Evaluating a case study using Bloom's taxonomy of education. AORNJ, v. 30, n. 88, p 390-402, 2008.

LÉLÉ, S.M. Sustainable Development: A critical Review. World development, v. 19, n. 6, p. 607-621, 1991.

LIPSCOMB, J. Is bloom's taxonomy better than intuitive judgment for classifying test questions? Education, v. 1, n. 106, p. 102. 1985.

LOMENA, M. Benjamin Bloom. Disponível em: <http://www.everything2.com/ index.pl?node_id=143987>. Acesso em: 10/07/2012.

LORD, T.; BAVISKAR, S. Moving students from information recitation to information understanding: exploiting Bloom's Taxonomy in creating Sciente Questions. Journal of College Science Teaching, 2007.

MATTAR, H. Publicação especial do Instituto Ethos sobre a Conferência Internacional. Empresas e Responsabilidade Social, 2008.

MONTEIRO, I. G.; TEIXEIRA, K. R. de M.; PORTO, R. G. Os níveis cognitivos da taxonomia de Bloom: existe necessariamente uma subordinação hierárquica entre eles? In: ENCONTRO DA ASSOCIAÇÃO NACIONAL DE PÓS-GRADUAÇÃO E PESQUISA EM ADMINISTRAÇÃO, 36., Rio de Janeiro. Anais... Rio de Janeiro: Anpad, 2012. p. 1 - 16. Disponível em:

$<$ http://www.anpad.org.br/evento.php?acao=trabalho\&cod_edicao_

subsecao $=848 \&$ cod_evento_edicao $=638$ cod_edicao_trabalho $=14711>$. Acesso em: $28 / 09 / 2012$.

MORETTO, V.P. Prova: um momento privilegiado de estudo, não um acerto de contas. 8.ed. Rio de Janeiro: Lamparina, 2008.

NOBLE, T. Integrating the revised bloom's taxonomy with multiple intelligences: A planning tool for curriculum differentiation. Teachers College Record, v. 1, n. 106, pp. 193211, 2004.

OTT, E.; CUNHA, J. V. A.; CORNACCHIONE JÚNIOR, E. B.; DE LUCA, M. M. M.; 
Relevância dos conhecimentos, habilidades e métodos instrucionais na perspectiva de estudantes e profissionais da área contábil: estudo comparativo internacional. In: ASSOCIAÇÃO NACIONAL DOS PROGRAMAS DE PÓS-GRADUAÇÃO EM CONTABILIDADE, 5., 2011, Vitória-ES. Anais... v. 22, n. 57, p. 338-356, 2011.

PATEL, V. L.; GROEN, G. J.; SCOTT, H. M. Biomedical knowledge in explanations of clinical problems by medical students. Medical Education, v. 22, 1988.

PATRUS-PENA, R.; CASTRO, P. P. Ética nos negócios: condições, desafios e riscos. São Paulo: Atlas, 2010.

PELISSONI, A. M. S. A avaliação no ensino superior: contextos e cenários. Programa Permanente de Capacitação Docente. Valinhos: Anhaguera Educacional, 2009.

ROMÃO, J. E. Avaliação Dialógica: Desafios e perspectivas. 6.ed. São Paulo: Cortez: Instituto Paulo Freire, 2005.

SALUME, P. K.; BRAGA, J. O.; LATINI, F. H.; CHEQUER, K. M.; GONÇALVEZ, R. F.; RIBEIRO, D. Q. O ENADE Avalia o Administrador de Acordo com o Perfil Exigido pelo MEC? Uma Análise sob a Perspectiva da Taxonomia de Bloom. In: ENCONTRO DA ASSOCIAÇÃO NACIONAL DE PÓS-GRADUAÇÃO E PESQUISA EM ADMINISTRAÇÃO, 36., 2012, Rio de Janeiro. Anais... EnAnpad. 2012.

SAMARA, B. S.; BARROS, J. C. de. Pesquisa de marketing: conceitos e metodologia. 4.ed. São Paulo: Pearson Education: Prentice Hall. 2009.

SWART, A. J. Evaluation of Final Examination Papers in Engineering: A Case Study Using Bloom's Taxonomy. IEEE Transactions on Education, v.53, n 2, p.257-264, 2010.

SENGE, P. M. A quinta disciplina: arte e prática da organização da aprendizagem. 16. ed. São Paulo: Best Seller, 2004.

STARR, C.W.; MANARIS, B.; STALVEY. Bloom's Taxonomy Revisited: Specifying Assessable Learning Objectives in Computer Science. Technical Symposium on Computer Science Education, p. 261-265, 2008.

ZANON, D. P.; ALTHAUS, M. 2008. Instrumentos de avaliação na prática pedagógica universitária. Disponível em: <http://www.maiza.com.br>. Acesso em: 07/04/2012.

ZHENG, A. Y.; LAWHORN, J. K.; LUMLEY, T.; FREEMAN, S. Assessment: application of Bloom's Taxonomy debunks the "MCAT Myth". Science, n. 319, p. 414-415, 2008.

WANG, C.L.; AHMED, P. K. Organizational learning: a critical review. The Learning Organization, v.10, n.1, p.8-17, 2003

\section{* Beneficiário de auxílio financeiro da CAPES e da FAPEMIG.}




\section{DADOS DOS AUTORES}

\section{ROBERTO PATRUS ${ }^{\star}$ robertopatrus@pucminas.br}

Doutor em Filosofia/ Administração pela Universidad Complutense de Madrid Instituição de vinculação: Pontifícia Universidade Católica de Minas Gerais / PPGA Belo Horizonte/MG - Brasil

Áreas de interesse em pesquisa: Ensino e Pesquisa em Administração e Ética.

*Av. Itaú, 525 Dom Cabral Belo Horizonte/MG 30535-012

\section{HELENA BELINTANI SHIGAKI belintanihs@gmail.com} Mestranda em Administração pela PUC/MG

Instituição de vinculação: Pontifícia Universidade Católica de Minas Gerais / PPGA Belo Horizonte/MG - Brasil

Áreas de interesse em pesquisa: Ensino e Pesquisa em Administração, Avaliação em Ensino Superior, Voluntarismo e Marketing.

\section{DANUSA DIAS REIS COUTINHO danusadrcoutinho@gmail.com.br} Mestranda em Administração pela PUC/MG

Instituição de vinculação: Pontifícia Universidade Católica de Minas Gerais / PPGA Belo Horizonte/MG - Brasil

Áreas de interesse em pesquisa: Ética, Desenvolvimento Sustentável, Governança e Parcerias Intersetoriais.

\section{CHRISTIANE VILLELA christianevillela_mktp@hotmail.com}

Mestranda em Administração pela PUC/MG

Instituição de vinculação: Pontifícia Universidade Católica de Minas Gerais / PPGA Belo Horizonte/MG - Brasil

Áreas de interesse em pesquisa: Marketing de Luxo (premium), Comportamento do Consumidor e Ética.

\section{GEORGIANA LUNA BATINGA georgianaluna@yahoo.com.br} Mestranda em Administração pela PUC/MG

Instituição de vinculação: Pontifícia Universidade Católica de Minas Gerais / PPGA Belo Horizonte/MG - Brasil

Áreas de interesse em pesquisa: Marketing, Comportamento do Consumidor, Gestão e Responsabilidade Socioambiental. 